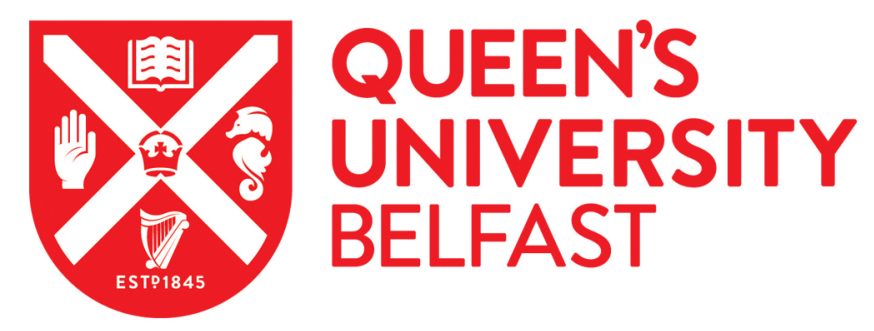

\title{
Probing P25 TiO2 Photocatalysis Using Photoinduced Absorption Spectroscopy (PIAS)
}

O'Rourke, C., \& Mills, A. (2021). Probing P25 TiO2 Photocatalysis Using Photoinduced Absorption Spectroscopy (PIAS). Chemical Communications, 57(10), 1242-1245. https://doi.org/10.1039/D0CC07794A

Published in:

Chemical Communications

Document Version:

Peer reviewed version

Queen's University Belfast - Research Portal:

Link to publication record in Queen's University Belfast Research Portal

Publisher rights

Copyright 2020 Royal Society of Chemistry. This work is made available online in accordance with the publisher's policies. Please refer to any applicable terms of use of the publisher.

\section{General rights}

Copyright for the publications made accessible via the Queen's University Belfast Research Portal is retained by the author(s) and / or other copyright owners and it is a condition of accessing these publications that users recognise and abide by the legal requirements associated with these rights.

Take down policy

The Research Portal is Queen's institutional repository that provides access to Queen's research output. Every effort has been made to ensure that content in the Research Portal does not infringe any person's rights, or applicable UK laws. If you discover content in the Research Portal that you believe breaches copyright or violates any law, please contact openaccess@qub.ac.uk. 


\title{
Probing $\mathrm{P} 25 \mathrm{TiO}_{2}$ Photocatalysis Using Photoinduced Absorption Spectroscopy (PIAS)
}

Received 00th January 20xx,

\author{
Christopher O'Rourke ${ }^{\mathrm{a}}$ and Andrew Mills*a
}

Accepted 00th January 20xx

DOI: $10.1039 / \times 0 x \times 00000 x$

Photoinduced absorption spectroscopy, PIAS, is used for the first time to probe the kinetics exhibited by the most commonly employed powder photocatalyst, $\mathrm{P25} \mathrm{TiO}_{2}$, in mesoporous film form, in the photocatalysed oxidation of a commonly used test organic pollutant, 4-chlorophenol, 4CP. The results show that PIAS can provide previously unobtainable, invaluable, direct kinetic, and mechanistic, information concerning photogenerated holes in powdered photocatalysts.

New photocatalytic materials are often first synthesised in powder form and usually tested for activity as powdered dispersions through steady-state irradiation studies. In commercial photocatalytic materials, such as self-cleaning glass $^{1}$, tiles ${ }^{2}$, paint ${ }^{3}$, concrete ${ }^{4}$ and plastics ${ }^{5}$, the primary function of the photocatalyst is invariably to destroy pollutants, $\mathrm{P}$, by sensitising their oxidative mineralisation by ambient $\mathrm{O}_{2}$. Under such circumstances, the overall photocatalytic reaction can be summarised as follows,

$$
\mathrm{P}+\mathrm{O}_{2} \underset{h v \geq E_{\mathrm{bg}}}{\stackrel{\mathrm{SC}}{\longrightarrow}} \text { Oxidation Products }
$$

where SC is the semiconductor photocatalyst and $E_{b g}$ is its bandgap. Most, if not all, current commercial photocatalytic products employ $\mathrm{TiO}_{2}$ as the semiconductor photocatalyst.

When a photocatalyst is used as a powder dispersion, the kinetics of reaction (1) are usually probed by measuring the initial rate of reaction under steady-state irradiation conditions as a function of different values of key reaction parameters such as the incident irradiance, $\rho$, and the bulk concentration of the pollutant, $[P]$; the concentration of $\mathrm{O}_{2}$ is usually fixed. The results of this work almost always fit an apparent LangmuirHinshelwood rate equation ${ }^{6,7}$, i.e.

$$
r_{i}=k_{p} \rho^{\theta}\left\{K^{*}[\mathrm{P}] /\left(1+K^{*}[\mathrm{P}]\right)\right\}
$$

where, $r_{i}$ is the initial rate of loss of $\mathrm{P}$, determined under steadystate irradiation conditions, $k_{p}$ is a proportionality constant, $\theta$ is

\footnotetext{
a. Queens University Belfast, School of Chemistry and Chemical Engineering, David Keir Building, Stranmillis Road, Belfast, UK, BT9 5AG.

Electronic Supplementary Information (ESI) available: See DOI: 10.1039/x0xx00000x
}

a power term, with a value that lies in the range $0.5 \leq \theta \leq 1$, depending upon the value of $\rho$ and the fraction of light absorbed, and $K^{*}{ }_{L}$ is the apparent Langmuir adsorption constant $^{6}$. The range of the value of $\theta$ is usually rationalised ${ }^{7,8}$ by noting that at low $\rho$, electron-hole recombination is inefficient, as the steady-state concentrations of $\mathrm{e}^{-}$and $\mathrm{h}^{+}$, i.e. $\left[\mathrm{e}^{-}\right]_{s s}$ and $\left[\mathrm{h}^{+}\right]_{s s}$, will be low, so that trapping and direct reaction with surface absorbed species is more likely than recombination, whereas at high $\rho$, both $\left[\mathrm{e}^{-}\right]_{\mathrm{ss}}$ and $\left[\mathrm{h}^{+}\right]_{\mathrm{ss}}$ will most likely be high and, as a consequence, recombination ${ }^{9}$ will be the dominant decay process $6,7,10$.

Many different mechanisms have been developed to provide a rationale for the apparent Langmuir-Hinshelwood kinetics exhibited by most semiconductor photocatalysts and described by eqn $(2)^{6}$. In most the assumption is made that the ratedetermining step, RDS, is either the direct oxidation of $\mathrm{P}$ by a photogenerated hole, $\mathrm{h}^{+}$, or an adsorbed hydroxyl radical, $\mathrm{OH} \bullet$, produced by $\mathrm{h}^{+}$, i.e.

$$
\mathrm{h}^{+} / \mathrm{OH} \bullet+\mathrm{P}_{\mathrm{ads}} \stackrel{\mathrm{k}_{\mathrm{RDS}}}{\longrightarrow} \text { Products }
$$

where $\mathrm{P}_{\text {ads }}$ is the concentration of the adsorbed pollutant (units: moles $\left.\mathrm{nm}^{-2}\right)^{6,10}$ In semiconductor photocatalysis, there is a significant body of evidence for $\mathrm{OH} \bullet$ generation $^{11-13}$, and it is usually assumed that under steady-state illumination their concentration, $[\mathrm{OH} \bullet]_{\mathrm{ss}}$ (units: moles $\mathrm{nm}^{-2}$ )., is directly related to that of $\left[\mathrm{h}^{+}\right]_{s s}$ (units: moles $\mathrm{nm}^{-2}$ ). ${ }^{6}$ As a consequence, in most reported mechanisms for SC photocatalysis, it is assumed that the initial rate associated with the RDS reaction (3), is given by the following simple expression ${ }^{6,7}$,

$$
r_{i}=k_{R D S}\left[\mathrm{~h}^{+}\right]_{s s}\left[\mathrm{P}_{\mathrm{ads}}\right]
$$

where, for reasons outlined above,

$$
\left[\mathrm{h}^{+}\right]_{\mathrm{ss}}=\alpha \rho^{\theta}
$$

where $\alpha$ is a proportionality constant. Unfortunately, the above two key assumptions, summarised by eqns (4) and (5), which underpin so many of the different proposed mechanisms for reaction (1), and the generally observed rate equation (2), remain just assumptions, since, to date, the direct measurement of $\left[\mathrm{h}^{+}\right]_{s s}$ in powdered semiconductor photocatalysts has not been possible. 
Recently, photoinduced absorption spectroscopy, PIAS, coupled with transient photocurrent (TC) measurements, which we shall refer to as PIAS/TC, have been used to probe the kinetics of water oxidation exhibited by a number of different semiconductor oxide photoanodes, including $\mathrm{TiO}_{2} .{ }^{14-17}$ In these PIAS/TC studies the optical absorption, $\Delta$ Abs $_{s s}$, exhibited by photogenerated holes accumulated at the surface of the semiconductor photoanode and the photocurrent, $J_{s s}$, are monitored under ultra-bandgap, steady-state irradiation conditions, and a large anodic bias. The latter is required to ensure surface electron-hole recombination is minimal, so that the overall fate of the surface accumulated holes is to react with water. In a typical set of experiments the values of $\Delta A b s_{s s}$ (monitored at a wavelength, $\lambda_{m}$, where the holes absorb strongly) and photocurrent, $J_{s s}$, are measured as a function of incident irradiance, $\rho$. A plot of $\log \left(J_{s s}\right)$ vs $\log \left(\Delta \mathrm{Abs}_{\mathrm{ss}}\right)$, for each photoanode tested in this way, yields the order of reaction, with respect to $h^{+}$, i.e. $n$, for water oxidation, since, under the large anodic bias,

$$
J_{s s}=k_{w}\left[\mathrm{~h}^{+}\right]^{n}
$$

where $k_{w}$ is the rate constant for the reaction of the steadystate photogenerated, long-lived, surface-accumulated holes, $\mathrm{h}^{+}{ }_{\mathrm{ss}}$, with water.

To date, the photoanodes used in PIAS/TC studies have been dense, flat films, and not the mesoporous films that a powder semiconductor photocatalyst would make. Indeed, previous work using transient absorption spectroscopy,TAS, has shown that when mesoporous $\mathrm{TiO}_{2}$ photoanodes are used under the same anodic bias as their flat, dense film counterparts, then after $10 \mu \mathrm{s}, 80 \%$ of the $\Delta$ Abs signal is lost due to electron-hole recombination ${ }^{16}$ which suggests that, if PIAS were to be used to probe such photoanodes, the values of $\triangle \mathrm{Abs}_{\mathrm{ss}}$ would most likely be too small to measure. However, this is not found to be the case in this work when using the most commonly used powder form of photocatalytic $\mathrm{TiO}_{2}$, namely $\mathrm{P} 25 \mathrm{TiO}_{2}$, which is considered to be a 'benchmark photocatalyst'. ${ }^{18}$ Thus, PIAS is, for the first time, used here to probe the reaction between steady-state irradiation generated holes on a P25 $\mathrm{TiO}_{2}$ photoanode or film and a commonly employed test organic pollutant, 4 chlorophenol, $4 \mathrm{CP}$, and by so doing, provide direct evidence of the first order dependence of rate upon $\left[\mathrm{h}^{+}\right]_{s s}$ and the latter's direct dependence upon $\rho^{\theta}$, where $0.5 \leq \theta \leq 1$, i.e. evidence for the two big assumptions that underpin ${ }^{6}$ many of the proposed mechanisms for the general photocatalytic mineralisation reaction (1).

The $\mathrm{P} 25 \mathrm{TiO}_{2}$ photoanodes used in this work were prepared using a slightly modified version of the method reported by Gratzel et al. ${ }^{19}$, details of which are given in S1 in the electronic supplementary information (ESI) file. Unless stated otherwise, all irradiations were carried out using $\mathrm{P} 25 \mathrm{TiO}_{2}$ films $(1.7 \mu \mathrm{m}$ thick) on FTO glass, i.e. glass with an electrically conducting, fluorine-doped tin oxide coating, in an Ar-saturated, $1 \mathrm{M} \mathrm{HClO}_{4}$ aqueous solution, which also contained $0.1 \mathrm{M} \mathrm{4CP}$. The roughness factor of the $\mathrm{P} 25 \mathrm{TiO}_{2}$ film was determined by dye adsorption to be ca. $33 .^{20}$

Linear sweep voltammograms (LSVs) of the $\mathrm{P} 25 \mathrm{TiO}_{2}$ electrode were recorded in the absence and presence of $0.1 \mathrm{M} \mathrm{4CP}$, with, and without UV irradiation ( $365 \mathrm{~nm}, 40 \mathrm{~mW} \mathrm{~cm}^{-2}$ ) from a UV (365 nm) LED (LED Engin, LZ1-10UV00-0000) and the results of this work are illustrated in Fig. 1.

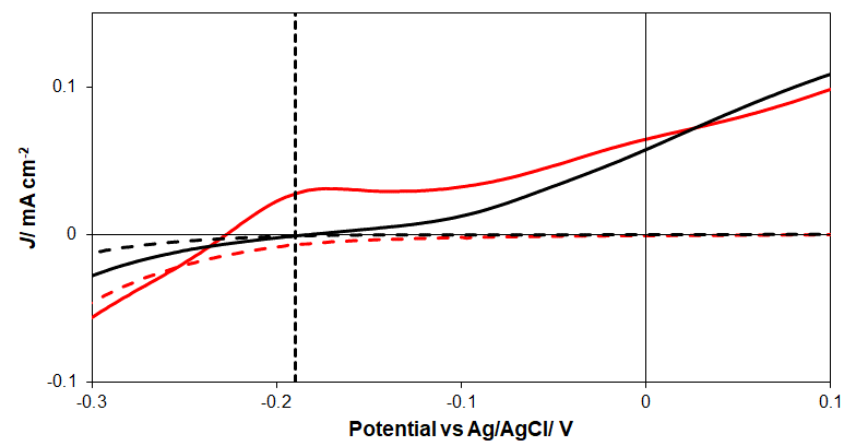

Fig. $1 \mathrm{LSV}^{\prime} \mathrm{s}\left(5 \mathrm{mV} \mathrm{s}^{-1}\right)$ recorded for a $\mathrm{P} 25 \mathrm{TiO}_{2}$ photoanode in the absence (black line) and presence (red line) of $0.1 \mathrm{M} 4 \mathrm{CP}$ (in $\mathrm{O}_{2}$-free, $1 \mathrm{M} \mathrm{HClO}_{4}$ ), with (solid line) and without (broken line) UV irradiation $\left(365 \mathrm{~nm}, 40 \mathrm{~mW} \mathrm{~cm}^{-2}\right.$ ).

These results show that in the absence of $4 \mathrm{CP}$ the onset of the photocurrent due to water oxidation occurs at ca. $-0.19 \mathrm{~V}$ vs $\mathrm{Ag} / \mathrm{AgCl}$, and that this onset (but now due to the photocatalysed oxidation of $4 \mathrm{CP}$ ) is shifted to $-0.24 \mathrm{~V}$ vs $\mathrm{Ag} / \mathrm{AgCl}$ when $0.1 \mathrm{M}$ 4CP is also present. Thus, in all subsequent PIAS/TC work reported here a polarising voltage of $-0.19 \mathrm{~V}$ vs $\mathrm{Ag} / \mathrm{AgCl}$ was employed so that the measured photocurrent was primarily (> 99\%) due to the oxidation of $4 \mathrm{CP}$, rather than water.

The $\mathrm{P} 25 \mathrm{TiO}_{2}$ photoanode polarised at $-0.19 \mathrm{~V} \mathrm{vs} \mathrm{Ag} / \mathrm{AgCl}$ was then probed using PIAS/TC, in which the $365 \mathrm{~nm}$ UV steadystate irradiance, was varied over the range 2 to $113 \mathrm{~mW} \mathrm{~cm}^{-2}$. In this work, a value for $\lambda_{m}=500 \mathrm{~nm}$ was used for monitoring the absorbance, Abs, due to the photogenerated holes on the P25 $\mathrm{TiO}_{2}$ anode, since other work carried out here on water oxidation using these same films, and by others using flat, dense $\mathrm{TiO}_{2}$ films ${ }^{16}$, revealed a maximum in the photoinduced absorption spectrum exhibited by the photogenerated holes on $\mathrm{TiO}_{2}$ at this wavelength. Results arising from this work, in the form of the observed variation in photocurrent, i.e. J, and change in absorbance at $500 \mathrm{~nm}, \Delta \mathrm{Abs}$, exhibited by the P25 $\mathrm{TiO}_{2}$ photoanode, as a function of time - before, during and after irradiation - are illustrated in Fig. 2(a) and (b) respectively. The photocurrent peaks at the beginning and end of the irradiation period illustrated in Fig. 2(a) are due to the initial extraction of photogenerated electrons from the film (to yield a steady-state level of photogenerated holes at the surface) and back electron flow - from the external circuit into the photoanode, due to back electron-hole recombination. ${ }^{16}$ The photocurrent peaks produced when the light is switched off will obviously be associated with a hole concentration, $\left[\mathrm{h}^{+}\right]_{\text {dark, }}$, that will make a contribution to the dark decay of $\Delta \mathrm{Abs}_{\mathrm{ss}}$ with time. However, integration of each photocurrent peak and division by the roughness factor yields a value for $\left[\mathrm{h}^{+}\right]_{\text {dark }}$ that is $<7 \%$ that of $\left[\mathrm{h}^{+}\right]_{\text {ss. }}$. Further details concerning these calculations are given in $\mathrm{S} 2$ in the ESI, which show that the decay kinetics exhibited by $\Delta \mathrm{Abs}_{\mathrm{ss}}$ at the end of each steady state irradiation, see Fig. 2(b). are due primarily (>93\%) to the photocatalysed oxidation of $4 C P$, as are the steady-state irradiation values of $J$ and $\Delta A b s$. 

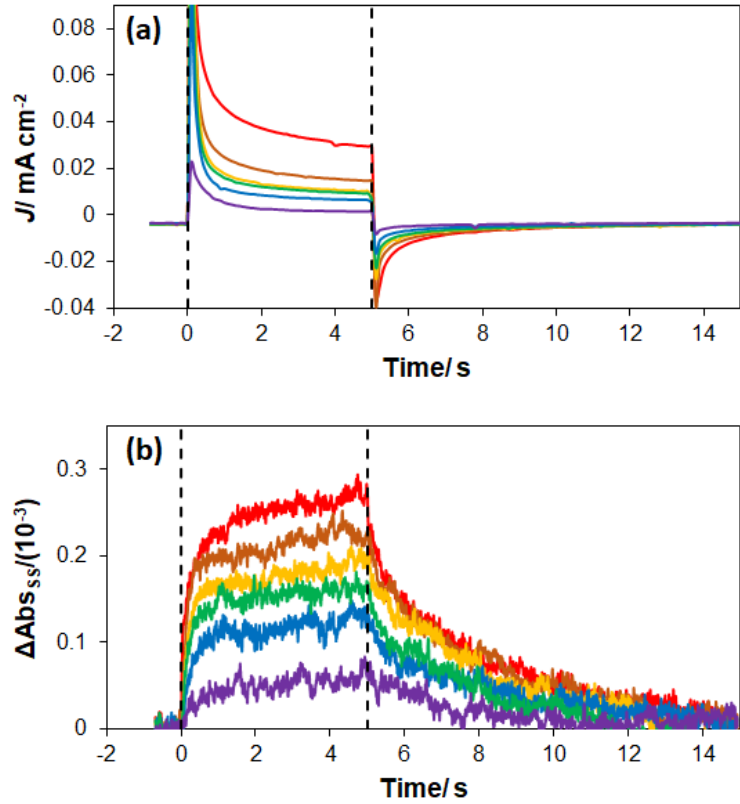

Fig 2 Plots of the measured (a) photocurrent, $J$, and (b) change in absorbance at at $-0.19 \mathrm{~V}$ vs Ag/AgCl and in $0.1 \mathrm{M} 4 \mathrm{CP}$ (in $\mathrm{O}_{2}$-free, $1 \mathrm{M} \mathrm{HClO}_{4}$, before, during and after steady state irradiation, produced using different $365 \mathrm{~nm}$ UV irradiances. In both plots the UV irradiances used were (from bottom to top): 113, 56, 36, 33, 21 and $6 \mathrm{~mW} \mathrm{~cm}^{-2}$, respectively. In (b), lines of best fit to the light-off decays all give excellent fits to first order kinetics with a 1st order rate constant, $\mathrm{k}_{1}=0.3 \mathrm{~s}^{-1}$.

As illustrated in Fig. 2, the above PIAS/TC study generated a series of different steady state irradiation values for the current, $J_{s s}$, and change in absorbance, $\Delta \mathrm{Abs}_{\mathrm{ss}}$, as a function of UV irradiance, $\rho$, the results of which are illustrated in Fig. 3(a).
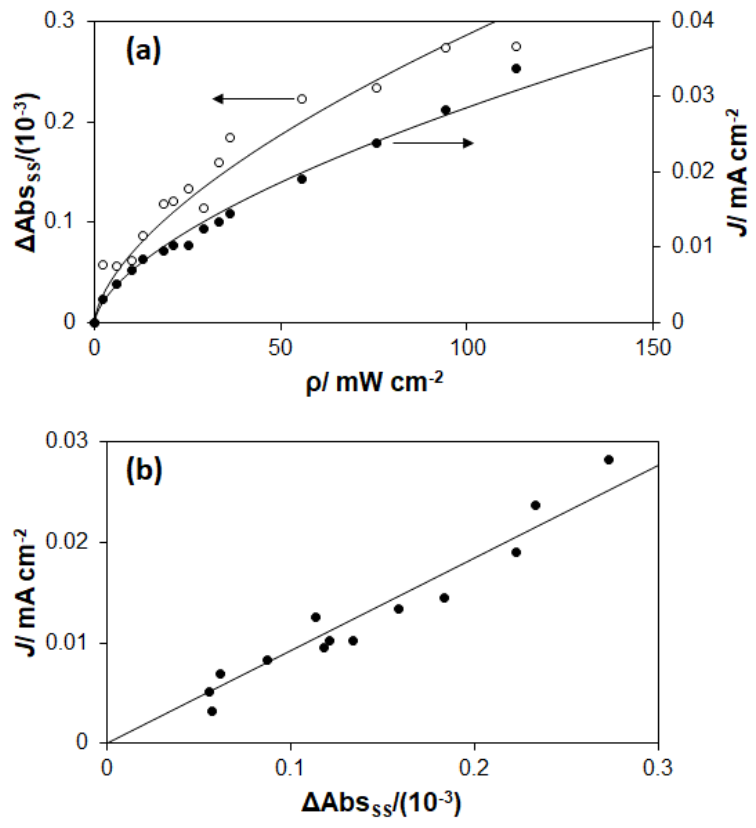

Fig 3 (a) Plots of the steady state photocurrents, $J_{s s}$ and the changes in absorbance $\triangle \mathrm{Abs}_{\mathrm{ss}}$, due to the photocatalysed oxidation of $4 \mathrm{CP}$ by a $\mathrm{P} 25 \mathrm{TiO}_{2}$ photoanode polarised at $-0.19 \mathrm{~V}$ vs $\mathrm{Ag} / \mathrm{AgCl}$ (in $\mathrm{O}_{2}$-free, $1 \mathrm{M} \mathrm{HClO}_{4}$ ), as a function of UV irradiance, $\rho$. In both profiles the solid lines of best fit have been calculated assuming $J_{s s}$ and $\Delta \mathrm{Abs}_{\mathrm{ss}}$ are proportional to $\rho^{\theta}$, where $\theta=0.60$; and (b) plot of $J_{s s}$ vs $\Delta \mathrm{Abs}_{\mathrm{ss}}$, revealing a good straight line with zero intercept.
4CP is one of the most widely employed test pollutants in photocatalytic research and the kinetics of its photocatalysed oxidation by $\mathrm{P} 25 \mathrm{TiO}_{2}$ powder dispersions is one of the most well-studied photocatalytic systems. ${ }^{6}$ In all the reports on this system, the kinetics fit the apparent Langmuir-Hinshelwood reaction rate equation, eqn (2), with the value of $\theta$ lying in the range $0.5 \leq \theta \leq 1 . .^{21,22}$ This also appears to be the case in this photoelectrochemical study, given that the good solid line fit to the rate (here $=J_{s s}$ ) vs. $\rho$ data, illustrated in Fig. 3(a), was calculated assuming $J_{s s}$ is proportional to $\rho^{\theta}$, where $\theta=0.60$. The good solid line fit to the $\Delta \mathrm{Abs}_{\mathrm{ss}}$ vs. $\rho$ data illustrated in Fig. 3(a), was also calculated assuming $\Delta \mathrm{Abs}_{\mathrm{ss}}$ is proportional to $\rho^{\theta}$, where $\theta=0.60$ and so provides direct evidence that $\left[\mathrm{h}^{+}\right]_{s \mathrm{~s}}$ is proportional to $\rho^{\theta}$, and a validation of eqn (5), which, as noted earlier, is one of the basic assumptions that underpin most reported mechanisms for semiconductor photocatalysis. ${ }^{6,7}$ However, the most striking outcome of the PIAS/TC study, arises from the plot of $J_{s s} v s \Delta$ Abs $_{s s}$, illustrated in Fig. $3(\mathrm{~b})$, which yields an excellent straight line, with a zero intercept, and shows that that the photocatalysed oxidation of $4 C P$, i.e. reaction (1), where $\mathrm{P}=4 \mathrm{CP}$, is first order with respect to $\Delta \mathrm{Abs}_{\mathrm{ss}}$, and so $\left[\mathrm{h}^{+}\right]_{\mathrm{ss}}$, i.e. $n=1$ in the RDS for the photocatalysed oxidation by the P25 $\mathrm{TiO}_{2}$ photoanode. This latter result provides direct evidence that reaction (3) is the rate determining step in this system, with a rate equation given by eqn (4), which is the second key assumption made in most reported mechanisms for semiconductor photocatalysis. ${ }^{6}$

In PIAS/TC studies of the oxidation of water by $\mathrm{Fe}_{2} \mathrm{O}_{3}$ and $\mathrm{BiVO}_{4}$ photoanodes, it has been shown that the order of reaction, $n$, can not only be gleaned from a plot of $\log \left(J_{s s}\right)$ vs $\log \left(\Delta A b s_{s s}\right)$, but also through the analysis of the $\Delta \mathrm{Abs}_{\mathrm{ss}}$ vs time decay traces observed once the UV LED is switched off. This feature is confirmed in this work through an examination of the measured decays of $\Delta$ Abs vs (dark) time, illustrated in Fig. 2(b), which all give a good fit to first order kinetics with the same rate constant, $\mathrm{k}_{1}=0.3 \mathrm{~s}^{-1}$. Thus, the dark decays illustrated in Fig. 2(a), support the steady-state findings described above and the nature of the RDS. It follows that it should also be possible to extend this method for determining reaction order when using photoanodes, to photocatalyst films in which the photogenerated electrons are not scavenged by an applied bias in an photoelectrochemical cell, but rather using a sacrificial electron acceptor, SEA.

The use of sacrificial electron acceptors, i.e. SEAs, such as $\mathrm{Ag}^{+}$or $\mathrm{Pt}$, or donors, such as methanol or PVA, is common in TAS studies of charge carrier dynamics in semiconductor films or colloids. ${ }^{23-25}$ However, to our knowledge the use of a sacrificial electron acceptor, instead of a potentiostat, to scavenge the photogenerated electrons in a PIAS study of a photocatalytic reaction has not been reported before. Thus, in this work, as in most photocatalytic studies, $\mathrm{O}_{2}$ was used as the SEA and a typical set of $\triangle \mathrm{Abs}_{\mathrm{ss}}$ vs time profiles arising from a PIAS study using an unbiased $\mathrm{P} 25 \mathrm{TiO}_{2}$ film are illustrated in Fig. 4. In this work, as before, $\Delta \mathrm{Abs}_{\mathrm{ss}}$ appears to be proportional to $\rho^{\theta}$, but with $\theta=$ ca. 0.50 , suggesting that the $\mathrm{O}_{2}$ is a less effective scavenger than a potentiostat biased at $-0.19 \mathrm{~V} v \mathrm{Ag} / \mathrm{AgCl}$. More importantly, all the $\Delta \mathrm{Abs}_{\mathrm{ss}}$ vs time decay traces observed 
when the UV LED is switched off exhibited $1^{\text {st }}$ order kinetics, i.e. $n=1$, with a first order rate constant $=0.29 \mathrm{~s}^{-1}$, which is near identical to the results found for the electrochemically biased film of $\mathrm{P} 25 \mathrm{TiO}_{2}$ and once again provides direct evidence that reaction (3) is the RDS. In the absence of $\mathrm{O}_{2}$ the transient absorbance was negligible.

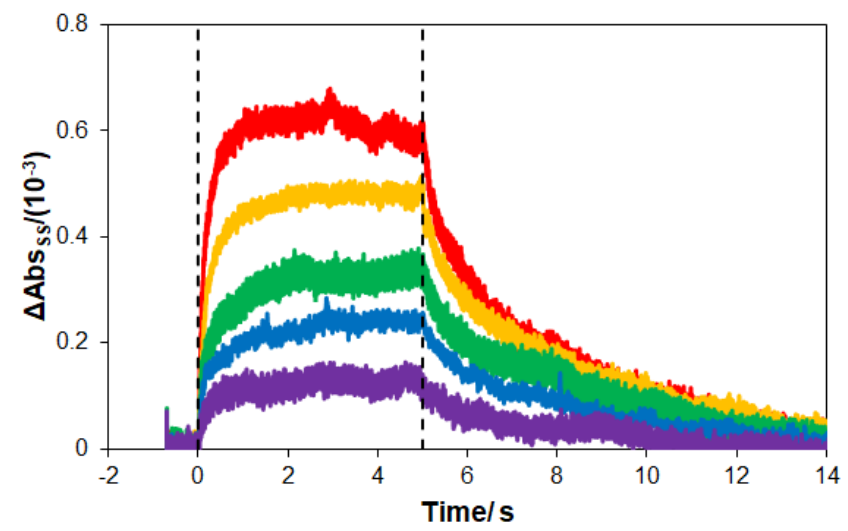

Fig. 4 Plots of the measured change in absorbance at $500 \mathrm{~nm}, \triangle \mathrm{Abs}$, as a function of time, exhibited by a $25 \mathrm{TiO}_{2}$ photoanode in $0.1 \mathrm{M} \mathrm{4CP}, \mathrm{O}_{2}$-saturated, $1 \mathrm{M}$ $\mathrm{HClO}_{4}$, solution, before during and after steady state irradiation, using different
$365 \mathrm{~nm}$ UV irradiances. The UV irradiances used were (from bottom to top): 76 , $365 \mathrm{~nm}$ and $2 \mathrm{~mW} \mathrm{~cm}^{-2}$ respectively. The lines of best fit to the light-off decays all' give excellent fits to first order kinetics with a 1st order rate constant, $\mathrm{k}_{1}=0.29$ $\mathrm{s}^{-1}$

In conclusion, PIAS/TC is used to probe the photocatalysed oxidation of a typical test organic pollutant, 4CP, by a film of P25 $\mathrm{TiO}_{2}$ powder particles. The study provides direct evidence that in this system: (i) the RDS is the reaction of a surfaceaccumulated photogenerated hole, or hydroxyl radical, with 4CP and (ii) the steady-state concentration of $\mathrm{h}^{+}$is proportional to $\rho^{\theta}$, where $0.5 \leq \theta \leq 1$, both of which are assumed in many of the reported mechanisms for photocatalysis. These same features are also demonstrated in a PIAS study of the same system, using an unbiased film of $\mathrm{P} 25 \mathrm{TiO}_{2}$ and $\mathrm{O}_{2}$ as a SEA.

\section{Author Contributions}

A.M. and C.O. contributed equally. All authors have given approval to the final version of the manuscript.

\section{Conflicts of interest}

There are no conflicts to declare.

\section{Notes and references}

1 Pilkington, https://www.pilkington.com/en$\mathrm{gb} / \mathrm{uk} /$ products/product-categories/self-cleaning/pilkingtonactiv-range, Accessed: December 2020.

2 Deutsche-Steinzeug, https://www.deutschesteinzeug.de/en/news/presse_und_news_detail.html?nd_re $\mathrm{f}=2530$, Accessed: December 2020.

3 STO, https://www.sto-sea.com/en/about-sto/stoinnovations/stocolor-climasan-/sto-climasan-color-.html, Accessed: December 2020
4 The Concrete Society, http://www.concrete.org.uk/fingertipsnuggets.asp?cmd=display\&id=826, Accessed: December 2020.

5 Taiyo Europe, https://taiyo-europe.com/wpcontent/uploads/2020/05/04.-Taiyo-Purify-MeshBrochure.pdf, Accessed: December 2020.

6 A. Mills, C. O'Rourke, K. Moore, J. Photochem. Photobiol. A: Chem., 2015, 310, 66. and references therein.

7 C. Turchi, D.F. Ollis, J. Catal., 1990, 122, 178

8 T.A. Egerton, C.J. King, J. Oil Col. Chem. Assoc., 1979, 62, 386.

9 H. Gerischer, Electrochim. Acta, 1995, 40, 1277.

10 D.F. Ollis, J. Phys. Chem. B, 2005, 109, 2439.

11 S. Tan, H. Feng, Y. Ji, Y. Wang, J. Zhao, A. Zhao, B. Wang, Y. Luo, J. Yang, J.G. Hou, J. Am. Chem. Soc., 2012, 134, 9978.

12 S.H. Szczepankiewicz, A.J. Colussi, M.R. Hoffmann, J. Phys. Chem. B, 2000, 104, 9842.

13 M.A. Grela, M.E.J. Coronel, A.J. Colussi, J. Phys. Chem., 1996, 100, 16940

14 F. Le Formal, E. Pastor, S.D. Tilley, C.A. Mesa, S.R. Pendlebury, M. Grätzel, J.R. Durrant, J. Am. Chem. Soc., 2015, 137, 6629.

15 Y. Ma, C.A. Mesa, E. Pastor, A. Kafizas, L. Francàs, F. Le Formal, S.R. Pendlebury, J.R. Durrant, ACS Energy Lett., 2016, 1, 618.

16 A. Kafizas, Y. Ma, E. Pastor, S.R. Pendlebury, C. Mesa, L. Francàs, F. Le Formal, N. Noor, M. Ling, C. Sotelo-Vazquez, C.J. Carmalt, I.P. Parkin, J.R. Durrant, ACS Catal., 2017, 7, 4896.

17 C.A. Mesa, L. Francàs, K.R. Yang, P. Garrido-Barros, E. Pastor, Y. Ma, A. Kafizas, T.E. Rosser, M.T. Mayer, E. Reisner, M. Grätzel, V.S. Batista, J.R. Durrant, Nature (Chemistry), 2020, 12,82 .

18 A. Kafizas, X. Wang, S.R. Pendlebury, P.R.F. Barnes, M. Ling, C. Sotelo-Vazquez, R. Quesada-Cabrera, C. Li, I.P. Parkin, J.R. Durrant, J. Phys. Chem. A, 2016, 120, 715.

19 S. Ito, P. Chen, P. Comte, M.K. Nazeeruddin, P. Liska, P. Pechy, M. Gratzel, Prog. Photovolt: Res. Appl., 2007, 15, 603.

20 A. Kay, I. Cesar, M. Gratzel, J. Am. Chem. Soc., 2008, 128, 15714.

21 A. Mills, S. Morris, J. Photochem. Photobiol. A: Chem., 1993, 71, 75.

22 G. Al-Sayyed, J.-C. D'Oliveira, P. Pichat, J. Photochem Photobiol. A: Chem., 1991, 58, 99.

23 T. Yoshihara, R. Katoh, A. Furube, Y. Tamaki, M. Murai, K. Hara, S. Murata, H. Arakawa, M. Tachiya, J. Phys. Chem. B, 2004, 108, 3817.

24 D. Bahnemann, A. Henglein, J. Lilie, L. Spanhel, J. Phys. Chem., $1984,88,709$.

25 J. Tang, J.R. Durrant, D.R. Klug, J. Am. Chem. Soc., 2008, 130, 13885. 